\title{
Competitividade e Isomorfismo: análise do perfil estrutural e financeiro-contábil de grandes cooperativas agropecuárias brasileiras ${ }^{1,2}$
}

\author{
Gustavo Leonardo Simão ${ }^{3}$, Cristina Lélis Leal Calegário ${ }^{4}$, \\ Luiz Marcelo Antonialli ${ }^{5}$ e Antônio Carlos dos Santos ${ }^{6}$
}

Resumo: Com as mudanças ocorridas no agronegócio, as cooperativas agropecuárias, pautadas por uma atuação local, com pouca agregação de valor, passaram a buscar novas formas de estruturação. Intentou-se identificar a estruturação e as peculiaridades financeiro-contábeis das cooperativas agropecuárias com maior volume de vendas no contexto brasileiro frente às organizações não cooperativas do mesmo segmento. O enfoque partiu de uma análise documental e da técnica contábil da análise vertical, bem como da utilização do teste de médias estatísticas Mann-Whitney com a finalidade de comparação das rubricas da DRE de um conjunto de 15 cooperativas e 14 empresas não cooperativas discriminadas como pertencentes ao conjunto de organizaçóes com maiores vendas no segmento de produção agropecuária em 2013. Os resultados confirmam a amplitude da estruturação em relação ao portfólio de negócios das cooperativas, visto a extensa atuação em diversificação concêntrica e conglomerada. Evidenciou-se, também, a paridade competitiva entre os segmentos de negócios analisados, principalmente pelo fato de não haver diferenças entre as taxas finais de "lucratividade". Ademais, há uma aparente refutação da ideia de que tal paridade competitiva se dá por uma orientação excessivamente voltada ao mercado, em detrimento de uma orientação social, haja vista os pontos diferenciadores verificados.

Palavras-chaves: Cooperativismo, gestão, modelo de negócio.
Abstract: Due to changes in agribusiness, agricultural cooperatives, guided by local operations, and with low added value, have been looking for new ways of structuring. We aimed to identify the forms of structuration and financial-accounting peculiarities
DOI - http://dx.doi.org/10.1590/1234-56781806-94790550104
1. Os autores agradecem o apoio financeiro do Conselho Nacional de Desenvolvimento Científico e Tecnológico (CNPq).
2. Data de submissão: 27 de maio de 2015. Data de aceite: 11 de setembro de 2016.
3. Universidade Federal de Lavras. Lavras, Minas Gerais - Brasil. E-mail: gustavo.simao@ufv.br
4. Universidade Federal de Lavras. Lavras, Minas Gerais - Brasil. E-mail: ccalegario@dae.ufla.br
5. Universidade Federal de Lavras. Lavras, Minas Gerais - Brasil. E-mail: lmantonialli@dae.ufla.br
6. Universidade Federal de Lavras. Lavras, Minas Gerais - Brasil. E-mail: acsantos@dae.ufla.br 
of agricultural cooperatives with higher volume of sales in the Brazilian context under the point of view of noncooperatives in the same segment. The work started with a documentary analysis and an accounting technique, named vertical analysis; in the next step, we used Mann-Whitney test to compare the formative lines of DRE of the a set of 15 cooperatives and 14 non-cooperative companies discriminated as belonging to organizations with higher sales in agricultural production in 2013. The results confirm the extent of the cooperatives structure in relation to the business portfolio, given the remarkable activities in concentric and conglomerate diversification. We observed the competitive parity between the business segments analyzed, mainly because there were no differences in the final rates of "profitability" when we compare the two cases. In addition, we can apparently refute the idea that this competitive parity is given by an orientation excessively directed to the market, at the expense of a social orientation, given the differentiating points externalized.

Key-words: business model, cooperativism, management.

Classificação JEL: Q13, Q14, L25.

\section{Introdução}

O movimento cooperativista, notavelmente do setor agropecuário, tem ao longo dos últimos anos incorporado cada vez mais processos voltados ao incremento de seus níveis de competitividade. Sabe-se que o contexto do agronegócio, principalmente no caso do Brasil, teve rápidas mudanças a partir da abertura comercial dos anos 1990 e do aumento nos valores pagos pelas commodities no mercado internacional do início do séc. XXI. Em decorrência de tal contexto, empresas locais passaram a competir com empresas multinacionais, variações cambiais passaram a afetar positiva e/ou negativamente a tendência das exportações, dentre outros fatores.

Nesse sentido, as cooperativas operantes no agronegócio, usualmente marcadas por uma atuação local, com pouca agregação de valor à sua produção, foram pressionadas a uma nova estruturação organizacional. Acentuou-se o processo de diversificação na cadeia produtiva, além da implementação de novos elos na cadeia de valor (verticalização). Esse cenário, no contexto do agronegócio cooperativo, veio acompanhado de uma expansão na área geográfica de atuação dessas organizações e do crescimento do quadro social (número de associados).

Essas novas taxonomias cooperativas, entendidas também como modelos de negócios, aparentemente sobrepujaram muito mais as variáveis econômicas do que variáveis políticas e/ou sociais. A perspectiva adotada é que a vitalidade econômica do negócio cooperativo, entendida principalmente por seus níveis de competitividade, propiciaria ao empreendimento condições de garantir seu papel social, apregoado pela doutrina cooperativista (WANG et al., 2012).

Todavia, determinados segmentos, inclusive acadêmicos, advogam que a estruturação de grandes cooperativas agropecuárias, atuando em extensas áreas geográficas e com elevado número de associados, tenderia a fazer com que o empreendimento se aproximasse cada vez mais da taxonomia de um empreendimento de capital não cooperativo. Estaria em voga, sob esta perspectiva, uma assimilação isomórfica das instituições do campo organizacional do agronegócio empresarial pelo cooperativismo agropecuário que culminaria com a transmutação das cooperativas em empresas de capital.

Ressalta-se, nesse sentido, que essa aparente contradição - se grandes empreendimentos coo- 
perativos conseguiriam obter competitividade frente àquelas organizações não cooperativas sem alterarem os padrões usualmente concebidos como os mais adequados ao negócio cooperativo de sucesso (atuação local, número reduzido de associados, dificuldade de tomada de decisão etc.) - apresenta-se como um campo ainda pouco estudado empiricamente, inclusive no cenário internacional, conforme ressaltam Mazzarol (2011) e Cechin et al. (2013).

Diante dessas discussões, a lacuna teórica que se coloca é que ainda não existem estudos relacionados à observação de como as grandes cooperativas estão estruturadas em relação ao seu portfólio de negócios e aos seus recursos financeiro-contábeis, neste último tópico destaque é dado ao fato de não se ter conhecimento acerca da competitividade dessas cooperativas quando comparadas às empresas não cooperativas. E, além disso, quais as possíveis implicações dessa estruturação em relação ao aspecto social, inerente à vertente social e política do movimento cooperativista.

Para apontar caminhos com vistas à supressão de tal lacuna, o presente trabalho objetivou analisar o perfil estrutural e financeiro-contábil de grandes cooperativas do setor de produção agropecuária brasileiro e analisar a competitividade desses empreendimentos em relação a empresas não cooperativas do mesmo segmento de negócios. Para tal, estruturou-se o trabalho nesta breve introdução, seguida por uma contextualização teórica acerca da complexidade de gestão dos empreendimentos cooperativos, inclusive pelo embate epistemológico inerente à dupla natureza cooperativa, de forma a delimitar os apontamentos reticentes em relação à consolidação de grandes empreendimentos cooperativos agropecuários. Além desses tópicos referenciais, há uma estruturação metodológica, seguida dos resultados e dos apontamentos finais.

\section{Fundamentação teórica}

\subsection{A cooperativa como uma organização complexa}

Há uma considerável despersonificação no âmbito do negócio cooperativo, o que invariavelmente torna o processo de gestão extremamente complexo (LEVI e DAVIS, 2008). Essa despersonalização relaciona-se à figura do associado, que ao mesmo tempo é cliente, fornecedor e proprietário; do gestor-associado, que é proprietário e administrador; e do gestor-contratado, que obtém resultados das operações, muitas das vezes, em detrimento dos próprios proprietários. Por outro lado, a própria estruturação do empreendimento também se coloca em um campo híbrido. Existem diferentes e, por vezes, conflitantes prescrições institucionais ambientais relacionadas ao empreendimento cooperativo.

Discorrendo sobre a dificuldade de gestão de empreendimentos sociais, como é o caso das cooperativas agropecuárias, Neck et al. (2009) afirmam que grande parte dessa complexidade advém da forma hibrida do negócio (Figura 1).

A complexidade das cooperativas se relaciona ao fato de elas terem emergido para estarem localizadas em uma intersecção central cuja pretensão seria balancear resultados econômicos e sociais (Figura 1). Em relação ao Quadrante 1, a principal proposta das cooperativas agropecuárias é tornar o acesso ao mercado mais fácil aos agricultores associados; nesse contexto, o principal problema a ser resolvido é uma produção individual insuficiente que permita seu escoamento a preços razoáveis. Há, portanto, uma evidente proposta social, voltada à melhoria da qualidade de vida dos associados mediante o preenchimento de uma falha de mercado. 
Figura 1. Tipologia de negócios

Missão do negócio

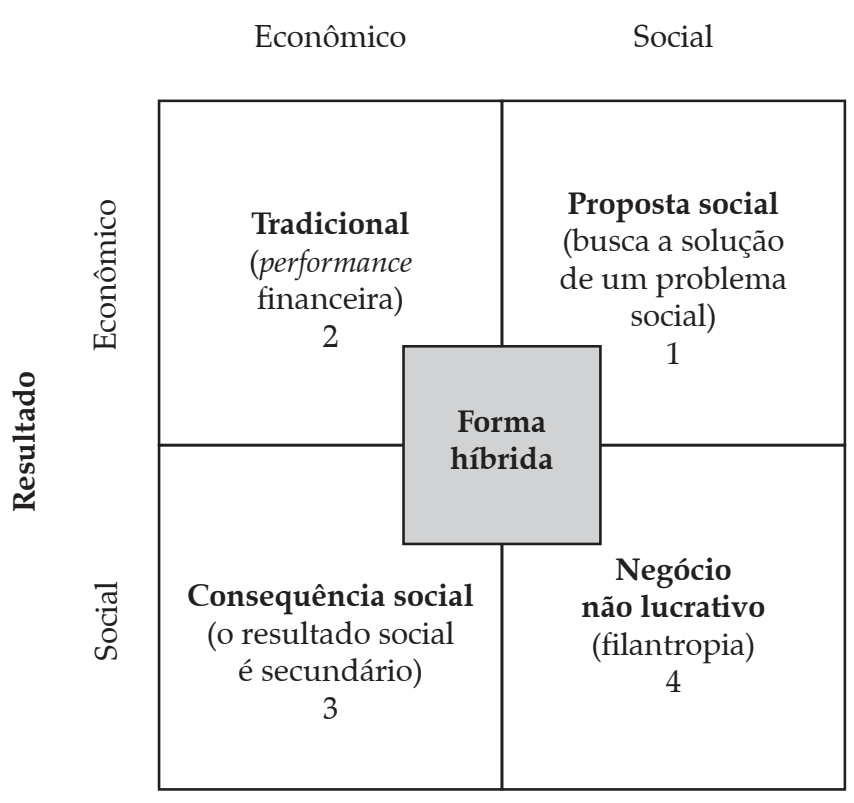

Fonte: Neck et al. (2009, p. 15).

Já no Quadrante 2, a cooperativa, enquanto empreendimento voltado à uma atividade econômica, deverá atentar-se para sua performance financeira, haja vista a intenção de seus associados, quando da filiação, na obtenção de melhores condições econômicas (retorno financeiro superior). Não somente em relação ao quadro social, mas igualmente importante é atender às demandas do ambiente externo, que também requer dessas organizações uma estruturação voltada à apresentação de níveis econômico-financeiros que demonstrem uma viabilidade do empreendimento.

Os princípios cooperativistas ressaltam que a organização também terá de desempenhar seu papel social, incrementando melhorias nas comunidades nas quais estão localizadas, além de preocupações socioambientais em decorrência de suas atividades. O foco do negócio, portanto, também se deve voltar para o desenvolvimento local (Quadrante 3).

Por fim, o empreendimento cooperativo terá de desenvolver atividades cuja missão seja de cunho social (natureza não econômica), voltada especificamente aos seus stakeholders, criando uma situação favorável para o surgimento da chamada práxis cooperativa, no sentido sociológico da palavra (Quadrante 4). Nesse último quadrante, ressaltam-se as atividades de desenvolvimento e organização do quadro social, sensibilização às práticas de fortalecimento da confiança, altruísmo, dentre outras.

É notória a externação, realizada por meio de constatações empíricas, de que, pela expansão do processo de globalização, há progressiva reestruturação do contexto econômico do agronegócio. Reardon et al. (1999), por exemplo, percebem que o comércio agroalimentar internacional, e interno em diversos países, foi impactado pela liberalização das transações transfronteiriças na segunda metade da década de 1980. Não somente a isso, Fulton e Giannakas (2013) ressaltam que o mercado agroalimentar (processamento, distribuição e varejo) está amplamente voltado para as inovações técnicas e por consumidores cada vez mais demandantes de produtos com alta qualidade. 
Houve, nesse sentido, além do acirramento concorrencial, uma mudança no padrão de produtos oferecidos, de um contexto marcado pelas commodities, para um cenário de produtos diferenciados, com agregação de valor. Hine et al. (2001) salientam a existência de uma pressão ambiental para a expansão das firmas em novas áreas geográficas, o que tem causado, de igual forma, uma demanda para que as cooperativas ampliem e atuem cada vez mais de maneira verticalizada e expandam sua atuação para áreas geográficas cada vez mais extensas.

Essa reestruturação das cooperativas agropecuárias perpassa, segundo constatação de Juliá-Igual et al. (2012), pelo denominador comum da ampliação do negócio, que é compreendida como questão necessária à ampliação da capacidade de negociação. Assim, as fusões, aquisições e formação de consórcios têm sido uma tendência estrutural no âmbito do cooperativismo (BIALOSKORSKI NETO, 2012).

De maneira geral, Kraatz e Block (2008) ressaltam que a forma como organizações pluralistas administram as tensões inerentes às demandas institucionais ambivalentes de seu campo organizacional (demandas macroambientais) e aquelas relacionadas aos anseios de seus atores internos (demandas microambientais) é ainda um mistério. Uma das principais preocupações nesse sentido está relacionada à credibilidade institucional. D'Aunno et al. (1991) denominam tal contexto de risco de legitimação. Segundo os referidos pesquisadores, a questão mais importante a ser resolvida, destacadamente pelo fato de a organização hibrida estar imersa em um contexto de múltiplas e não coordenadas fontes de legitimação, é buscar um equilíbrio mínimo necessário para não malograr nenhum dos aspectos, mas, também, não inviabilizar suas ações.

As dificuldades práticas, enfrentadas pelas organizações cooperativas, no sentido de se situarem na intersecção desse espectro de objetivos e atuações, por vezes, conflitantes, tem criado inúmeras discussões entre os pesquisadores da área acerca da impossibilidade e/ou inviabilidade de seu pleno atendimento. Ou seja, existem supo- sições de que o ponto de equilíbrio da tipologia híbrida seria uma perspectiva utópica, na melhor das hipóteses uma tendência didática, haja vista a impossibilidade de balancear as ambições contraditórias dos associados, as variáveis sociais e econômicas do negócio cooperativo e de seu ambiente de atuação (WANG et al., 2011; BOONE e OZCAN, 2014).

\subsection{O embate epistemológico entre uma atuação social versus econômica}

O ponto ótimo de atuação do negócio cooperativo seria justamente a busca de todos os objetivos definidos pelos campos organizacionais ao qual o empreendimento possui relações, e, também, em relação às pretensões internas de seu quadro social. Todavia, nesse rol de objetivações, existem perspectivas conflitantes que são difíceis de serem buscadas em conjunto. ${ }^{7}$ Destarte, a questão que se coloca é que tal equilíbrio não é algo facilmente factível, o que inicia embates epistemológicos em relação à natureza do negócio cooperativo.

O empreendimento cooperativo, a partir dos cenários traçados por essa perspectiva epistemológica, estaria em um contexto que funcionaria aparentemente como um pêndulo, ora defendido como um negócio a enfatizar o aspecto social, conforme percebido em Centner (1988) Michels (2000) e Planas e Valls-Junyent (2011); ora como um empreendimento cujo caráter econômico deveria ser o norte principal, como apontando em Enke (1945) e Bialoskorski Neto (2008) (Figura 2). Tal dualidade conflituosa não é contemporânea: Hogeland (2006) externa que a disputa entre o caráter social e o econômico tem raízes na própria história de surgimento do movimento cooperativo.

7. Segundo Nilsson (1999), um grande número de cooperativas nestas duas últimas décadas implementou novos padrões organizacionais com expressivas mudanças em relação ao que se denomina de cooperativas tradicionais (modelo emergido no meio do século XIX). 
Figura 2. Representação esquemática da contextualização econômica e social das cooperativas

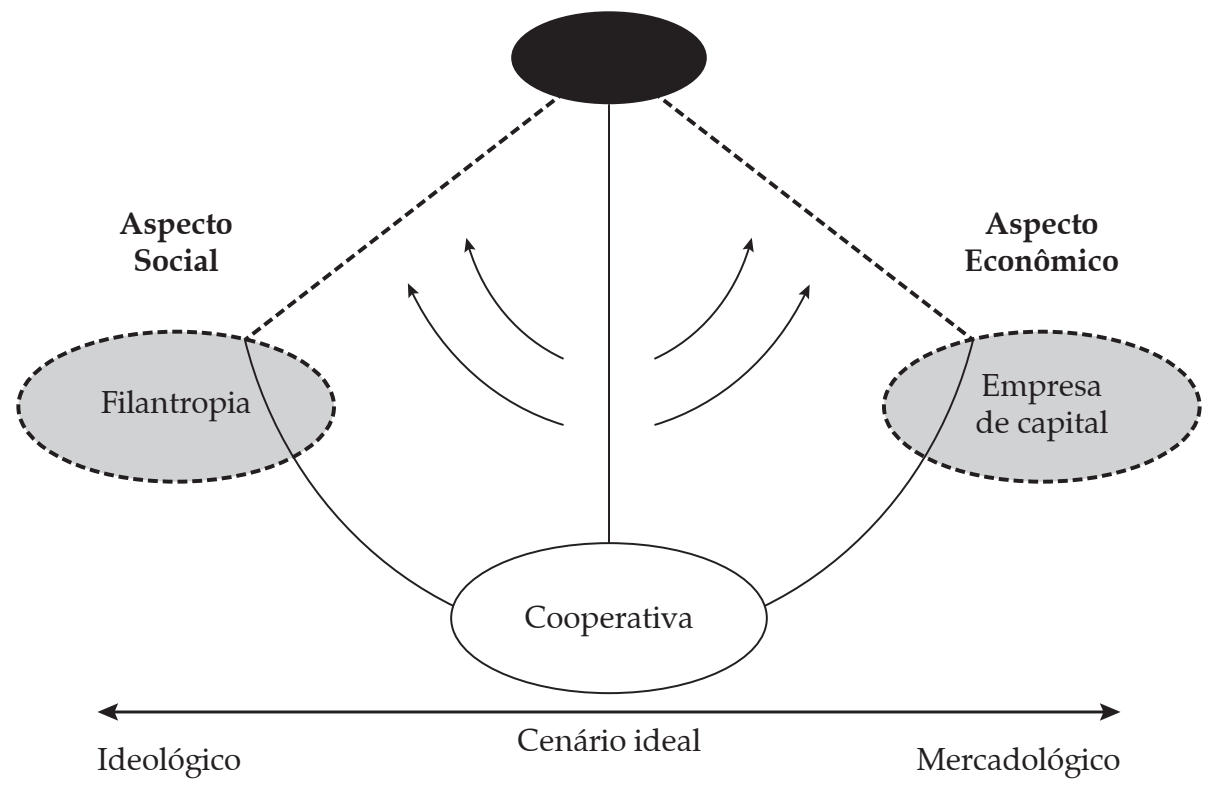

Fonte: Elaboração própria.

\subsection{A preponderância da vertente economia enquanto perspectiva para acompanhar as tendências ambientais}

Emelianoff (1942) e Boland et al. (2011) caracterizam as cooperativas agropecuárias como a integração das unidades econômicas de seus associados voltadas à busca de competitividade, por meio do negócio associativo. Há, portanto, por extrapolação, uma clara indicação da necessidade de a organização cooperativa empreender ações para a busca de credibilidade frente ao seu campo organizacional externo. Tal credibilidade perpassa invariavelmente pela evidenciação de um caráter competitivo que afaste a inferência de que as cooperativas são empreendimentos estruturalmente ultrapassados e, portanto, fadados ao fracasso nessa conjuntura contemporânea do agronegócio (CRÚZIO, 1999; PLANAS e VALLSJUNYENT, 2011).

Entende-se que o principal ponto norteador do movimento cooperativo é a correção de falhas de mercado, que só serão efetivamente alcançadas mediante a viabilidade econômica do empreendimento que, por extensão, remete-se à própria viabilidade das unidades de seus associados. Caberia, assim, à organização cooperativa a assimilação de práticas voltadas ao incremento de competitividade mercadológica. A orientação nessa perspectiva é pautada pelo mercado, mas a variável meio passa pelo entendimento de que a cooperativa é a própria junção das unidades de seus associados e, por isso, não deve agir em detrimento dessas. ${ }^{8}$

A partir de tal contextualização, algumas tendências estruturais são traçadas em resposta às mudanças ambientais (mudanças mercadológicas). Bekkum (2001) esquematizou o que se denominou de Modelo de Cubo Cooperativo. A referida estruturação retrata os diversos modelos de negócios cooperativos (Figura 3).

Conforme se percebe, na Figura 3, quatro estruturações básicas de cooperativas agropecuárias foram evidenciadas, quais sejam: cooperativas locais, cooperativas de commodities, cooperativas de nichos e cooperativas de valor

8. O entendimento perpassa o que Wang et al. (2012) externam ao inferirem que o nível de eficiência operacional da cooperativa afetará diretamente a eficiência das unidades agropecuárias de seus associados. 
Figura 3. Modelo de Cubo Cooperativo: estratégia e estrutura em três dimensões

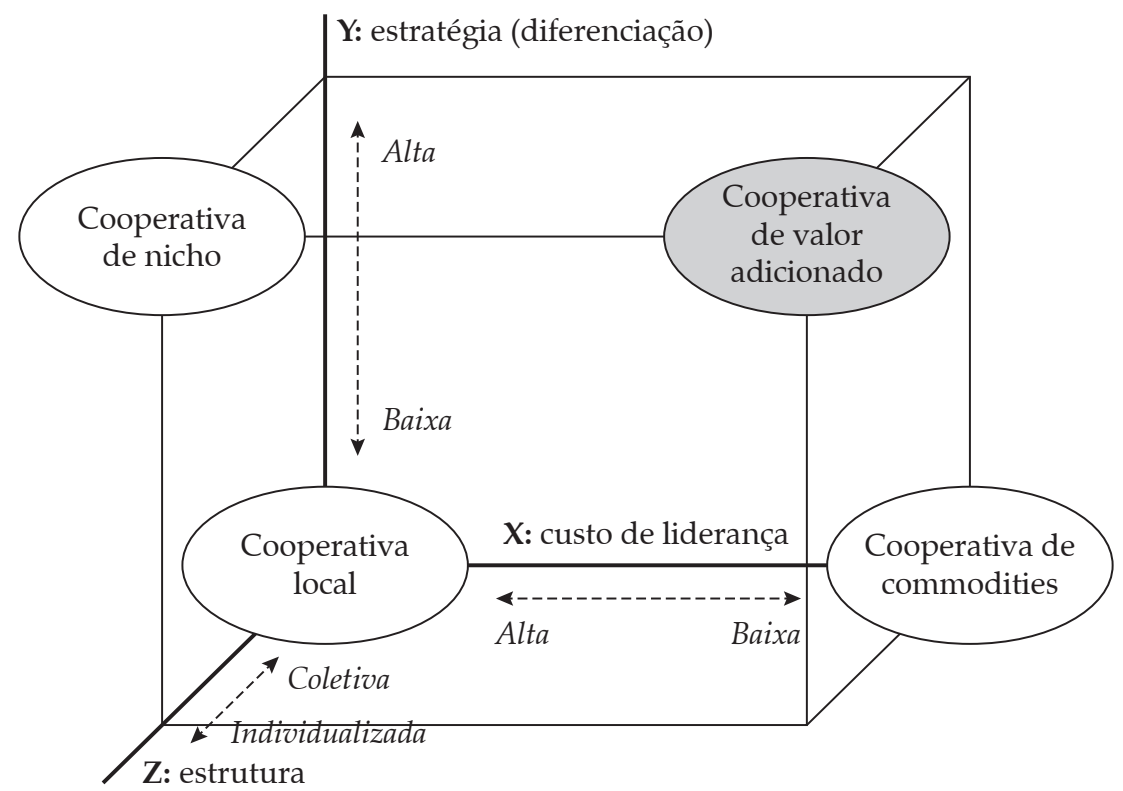

Fonte: Bekkum (2001, p. 49).

adicionado9. Bekkum (2001) ressalta, todavia, que as cooperativas de valor adicionado seriam aquelas mais aptas a enfrentarem mercados em ascensão concorrencial, na medida em que, sob tal estruturação, dentre outros fatores, se busca uma posição dominante.

As necessidades do mercado interpõem às cooperativas um maior controle da oferta, incremento de capital, seletividade do quadro social, poder de mercado, coordenação vertical, necessidade de financiamento, expansão da área de atuação, dentre outras questões (FULTON e GINNAKAS, 2013). Posição semelhante é defendida por Valentinov (2007), segundo o qual o aumento da intensidade competitiva obriga as cooperativas a buscarem flexibilidade estrutural, sob pena de comprometer a própria responsabilidade de retorno para com seus associados.

A questão problemática, que acirra o debate epistemológico em relação à natureza da orga-

9. A taxonomia de cooperativas de valor adicionado é entendida como a organização cooperativa com extensa cadeia de valor (produção agregada), diferenciação e com a formação de uma marca própria. nização cooperativa, diz respeito ao conjunto de inferências de que essas "novas estratégias" ocorreriam por uma assimilação passiva de práticas mercadológicas do campo organizacional do agronegócio. Assim, para conseguir a credibilidade institucional, as cooperativas estariam a incorporar prescrições não adequadas à sua natureza, que em último grau afetariam justamente a sustentabilidade do empreendimento.

\subsection{A acusação de assimilação isomórfica de práticas empresariais pelas cooperativas agropecuárias}

Preocupados com uma possível renúncia dos preceitos doutrinários diante dessas novas estruturações cooperativas, com destaque para a necessidade de identificação do associado para com seu negócio e da manutenção de níveis densos de capital social, diversos teóricos têm prenunciado a existência de uma distorção do modelo cooperativista, principalmente sob o argumento da existência de assimilações isomórficas do contexto de mercado não cooperativo, com destaque 
para tendências relacionadas à ampliação da atuação do negócio cooperativo.

$\mathrm{Na}$ maioria das vezes, tais pesquisadores compreendem que uma cooperativa não tem que ser competitiva em relação ao mercado, ela deverá propiciar uma boa convivência para com seus associados. Michels (2000), por exemplo, afirma que a perspectiva social é a mais importante, discorrendo que para o empreendimento cooperativo alcançar sucesso é imprescindível que ele demonstre um caráter de autoajuda, autorresponsabilidade e princípios de democracia por essência. Posição semelhante é defendida por Rios (2006), ao afirmar que o mais importante do cooperativismo não está atrelado a ganhos econômicos, e sim, aos ganhos sociais.

Puusa et al. (2013) percebem que as cooperativas têm invariavelmente assimilado tendências capitalistas. O risco desse contexto é, conforme ressalta Amodeo (1999), ao discorrer sobre o trabalho de Hirschman, tais empreendimentos desvalorizarem os critérios de lealdade e confiança, minimizando os mecanismos de voz, aos quais os associados têm direito.

Nesse mesmo sentido, Trechter et al. (2002) afirmam que, quando o empreendimento passa a ser pautado unicamente pelo aspecto da competitividade, há perda do capital social e, por consequência, do sentido de pertencimento ao negócio por parte do cooperado. Levi e Davis (2008), corroborando com a ideia, acreditam que há um isomorfismo incongruente em relação à estruturação de grandes cooperativas, única e exclusivamente sobre a defesa de incrementos competitivos.

Especificamente em relação à ampliação das áreas de atuação e do número de associados, grande crítica é dada por Cechin et al. (2013a) e Nilsson et al. $(2012)^{10}$. Tais pesquisadores ressaltam que a incorporação de grande número de associados, processos de diversificação da produção e a implementação de práticas de governança

10. Na visão dos autores, na maioria dos casos, tanto estratégias de integração vertical quanto horizontal diminuem os níveis de capital social (níveis de confiança dos membros para com a organização e entre eles) das cooperativas agropecuárias. corporativa seriam efeitos negativos que dificultariam a definição dos objetivos de atuação e das vantagens da ação coletiva, acarretando a inviabilidade do negócio, pela acentuação dos custos de transação e perda da proximidade necessária ao fortalecimento do capital social junto ao quadro de associados.

Diante dessas aparentes contradições, Chaddad e Iliopoulos (2013), Bijman (2013), Novkovic (2012) e Nilsson (1999) ressaltam a necessidade premente da busca por uma compreensão mais profunda, dada a incipiência de estudos relacionados ao tema, acerca das características diferenciadoras dessas taxonomias cooperativas contemporâneas, destacadamente em relação aos grandes empreendimentos cooperativos. Tal necessidade se dá em virtude do desconhecimento dos atributos estratégicos utilizados e da performance alcançada (BENOS et al., 2007).

É preciso, portanto, analisar como as grandes organizações cooperativas, com posições de mercado dominante, atuam em relação às prescrições epistemológicas da natureza da organização cooperativa e analisar a performance alcançada por esses empreendimentos em relação àqueles de capital (não cooperativos), notavelmente no sentido de indicar possíveis concordâncias com Fulton e Giannakas (2013), haja vista a inferência de uma própria alteração na natureza da Teoria Cooperativista.

\section{Procedimentos metodológicos}

A presente pesquisa, de natureza quantitativo-descritiva, visou, num primeiro momento, analisar a estruturação organizacional daquelas cooperativas brasileiras consideradas dentre as maiores organizações do setor de Produção Agropecuária em 2013. O ranking dessas cooperativas foi obtido a partir da publicação da Revista Exame - Edição Maiores e Melhores de 2013 (EDITORA ABRIL, 2013).

A função principal da referida publicação é elencar os empreendimentos de diversos setores econômicos que se destacaram em volume 
total de vendas (em milhões de dólares) no respectivo ano de análise. Destaca-se que a referida publicação é usualmente utilizada por pesquisadores para análises secundárias, como se percebe em Antunes et al. (2004), D'Angelo et al. (2006) e Cardoso et al. (2013).

Nesse sentido, percebeu-se que, dentre todas as organizações evidenciadas na classificação da mencionada publicação, para o setor de Produção Agropecuária, havia 40 (quarenta) cooperativas. A partir dessa constatação buscou-se por meio da pesquisa documental, e também via contato direto (e-mail e telefone), as demonstrações contábeis referentes a 2013, que foi o ano levado em consideração pelo ranking da publicação. Obtiveram-se dados referentes a 15 cooperativas, o que corresponde a uma taxa amostral de 37,5\% do total de organizações com essa caracterização.

Com o intuito de analisar o padrão dos resultados financeiros das cooperativas em que houve a disponibilização das demonstrações contábeis, realizou-se a análise vertical das DRE's dessas cooperativas. A análise vertical, na concepção de Assaf Neto (2012), é um processo comparativo, "expresso em porcentagem, que se aplica ao se relacionar uma conta ou grupo de contas com um valor afim ou relacionável, identificado no mesmo demonstrativo" (p. 113). Martins et al. (2012) defendem, ainda, que apesar da possibilidade de análise em todas as demonstrações financeiras, a análise vertical mostra-se mais eficaz na Demonstração de Resultado do Exercício (DRE).

A eficácia de se analisar a DRE se deve ao fato de que, conforme ressalta Silva (2012), torna-se possível a identificação da situação operacional da organização em determinado período, notavelmente em relação às suas rubricas de receitas, custos e/ou despesas. Destaca-se o fato de que o item de referência para as análises percentuais, no presente trabalho, foi a rubrica de Receita Líquida ${ }^{11}$.

11. Todos os valores de cada uma das rubricas da DRE foram alterados para valores percentuais, em planilha eletrônica, tomando-se como base referencial $(100 \%)$ o item de Receita Líquida.
Deste modo, todas as DRE's das 15 cooperativas foram discriminadas em planilha eletrônica separadamente (cada cooperativa em uma planilha) e seus valores convertidos em percentagem, com base na rubrica de Receita Líquida. Ademais, criou-se também uma planilha final na qual foi possível a visualização de uma DRE com os valores percentuais médios (valor médio consolidado).

Com a intenção de comparar os resultados obtidos nas análises financeiro-contábil das cooperativas, intentou-se o levantamento das demonstrações contábeis de 2013 no conjunto de empresas não cooperativas elencadas no mesmo ranking e setor produtivo da publicação utilizada para a seleção das cooperativas.

No âmbito das empresas não cooperativas, a disponibilidade das informações contábeis obteve retorno menor. A busca dos dados obteve sucesso somente junto ao conjunto de organizações de sociedade anônima figurantes no ranking. Assim, de 57 empresas não cooperativas, a busca para o presente trabalho identificou 22 balanços contábeis dos quais dois apresentavam ano fiscal distinto do parâmetro previamente definido ( $1^{\mathrm{o}} \mathrm{de}$ janeiro a 31 de dezembro de 2013), e seis apresentaram prejuízo (nenhuma das cooperativas se enquadrou nesse quesito). A análise final compreendeu, dessa forma, uma amostra de 14 organizações não cooperativas, o que representa $24,5 \%$ do total de empresas desta taxonomia (empresa não cooperativa).

A partir da análise vertical da DRE e de suas possíveis interpretações iniciais do segmento cooperativista, foi realizada a análise vertical das empresas não cooperativas com os mesmos padrões adotados quando da análise das cooperativas. As DRE's das empresas não cooperativas foram alocadas, cada uma em uma planilha, e os seus valores financeiros foram transmutados em percentuais com base na rubrica de Receita Líquida.

Realizada a discriminação da análise vertical para cada uma das organizações cooperativas e não cooperativas, utilizou-se do teste de Mann-Whitney para médias independentes a fim de 
se verificar estatisticamente diferenças entre os dois grupamentos (cooperativas e empresas não cooperativas) em cada uma das rubricas da DRE. $\mathrm{O}$ intento foi, portanto, analisar diferenças estatísticas entre os valores percentuais obtidos com a análise vertical, para cada uma das rubricas constituintes do grupamento de cooperativas e empresas não cooperativas. Foram, portanto, considerados os valores percentuais obtidos na análise vertical em cada um dos casos, respeitando-se os grupamentos diferenciadores (cooperativas e não cooperativas).

Segundo Field (2009), o teste de Mann-Whitney é apropriado para comparar as médias de dois grupos independentes para determinadas condições mútuas, notavelmente quando o grupo a ser comparado não assume condição de normalidade. Há de se ressaltar, mais uma vez, que o teste teve por finalidade parear e diferenciar estatisticamente cada uma das rubricas da DRE, de organizações cooperativas e não cooperativas. Assim, foi o responsável por apontar a existência ou não de diferenças contábeis entre esses dois segmentos de organizações para cada um dos itens formativos da demonstração contábil em análise, tendo sido realizado por meio do software estatístico SPSS versão 20.

Destaca-se o fato de que a premissa basilar da análise vertical e do teste estatístico partiu da inferência de que a DRE é um instrumento de percepção da competitividade de empreendimentos em determinado período, conforme comprovam Takamatsu et al. (2008) e Santos e Lustosa (2008).

\section{Resultados e discussão}

Para atingir os objetivos propostos neste trabalho, a presente seção está organizada da seguinte forma: apresentação descritiva das cooperativas analisadas, cujos pontos centrais estarão nas atividades econômicas principais e secundárias; apresentação dos resultados inerentes às visualizações da Demonstração do Resultado de Exercício (DRE) com valores médios para as cooperativas analisa- das, e suas possíveis interpretações; e a comparação das médias de cada uma das rubricas da DRE das cooperativas com as empresas não cooperativas analisadas por meio de tratamento estatístico, seguida de suas possíveis interpretações.

\subsection{O foco de atuação das cooperativas pesquisadas}

Em relação à descrição da atividade econômica das cooperativas pesquisadas, conforme se observa no Quadro 1, grande parte apresenta portfólio extenso de atuação no agronegócio. Tal atuação dá-se tanto no contexto da verticalização, com a industrialização e distribuição de commodities, quanto em atividades rurais correlacionadas, que Souza e Braga (2007) denominaram de processo de diferenciação concêntrica.

Há, conforme ressaltam Serigati e Azevedo (2013) e Bijman et al. (2013), a predominância de uma cadeia de valor diversificada. Infere-se, a partir dessa análise descritiva, que a diferenciação concêntrica é uma precondição para organizações cooperativas do setor de produção agropecuária obterem volume de vendas passíveis de comparação (em relação à obtenção de patamares competitivos satisfatórios) com as de organizações não cooperativas.

O Quadro 2 apresenta, a partir da pesquisa documental realizada, as atividades econômicas, no contexto das cooperativas pesquisadas, não diretamente relacionadas à atividade principal do negócio. Destaca-se o varejo, com a presença de supermercados e postos de combustíveis. Esse processo de diversificação é denominado por Britto (2013) de diversificação conglomerada, ou seja, quando não existe, aparentemente, relação das atividades secundárias com a atividade econômica principal do empreendimento.

$O$ investimento na diversificação por conglomerado estaria relacionado a ganhos complementares, principalmente pela identificação de oportunidades de nichos de mercado não atendidos, inclusive e principalmente em relação ao próprio corpo de associados da cooperativa. 


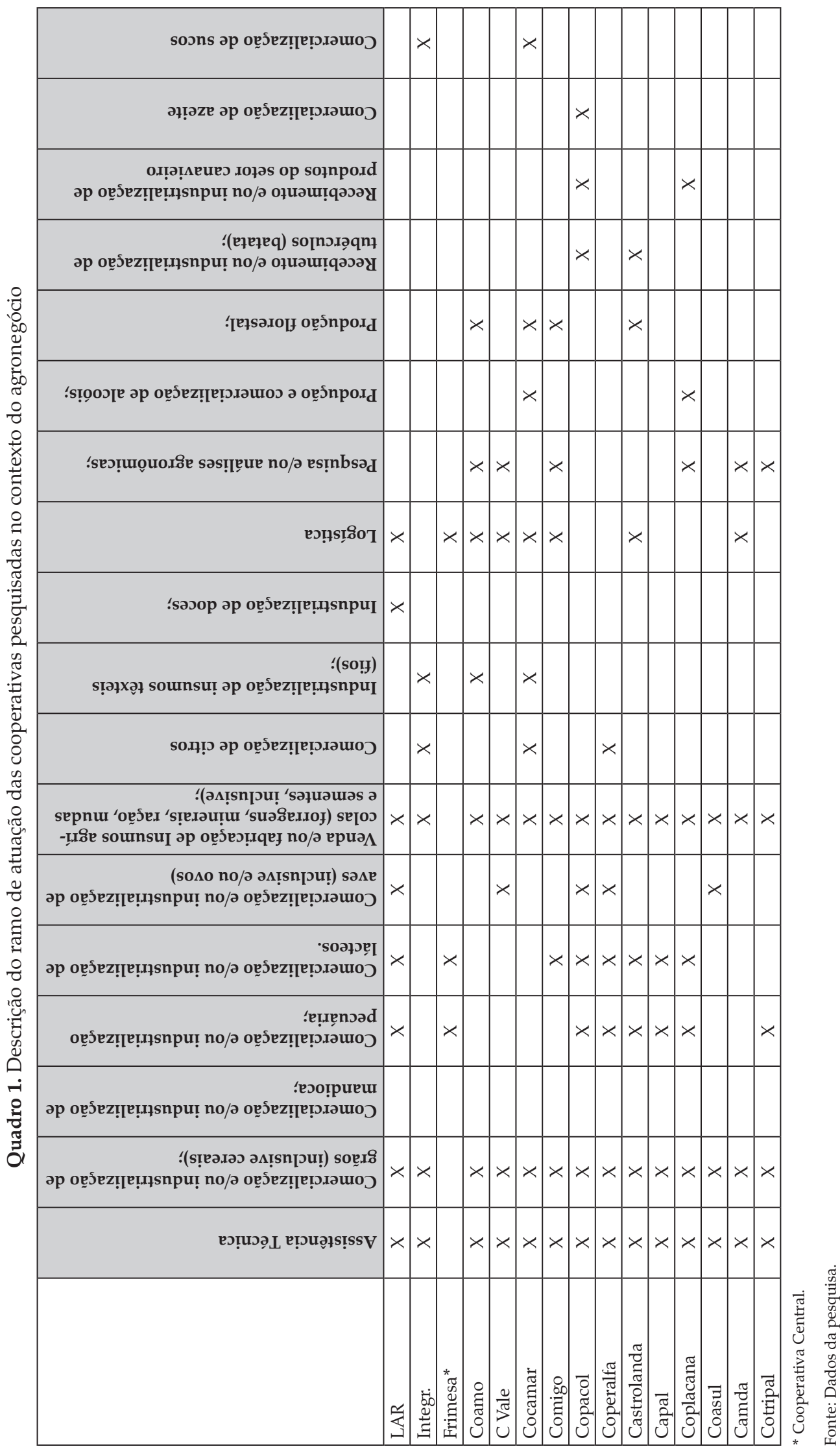


076 - Competitividade e Isomorfismo: análise do perfil estrutural e financeiro-contábil de grandes cooperativas agropecuárias brasileiras

Quadro 2. Diversificação conglomerada (secundária) das cooperativas pesquisadas

\begin{tabular}{|c|c|c|c|c|c|c|c|c|c|c|c|c|}
\hline & 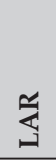 & $\begin{array}{l}\text { ह } \\
\text { ठ }\end{array}$ & $\frac{\stackrel{0}{\pi}}{\mathrm{s}}$ & $\begin{array}{l}\text { ฮี } \\
\text { ฮँ }\end{array}$ & 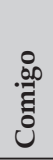 & $\begin{array}{l}\overline{0} \\
\tilde{\tilde{J}} \\
\tilde{\delta}\end{array}$ & 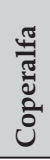 & 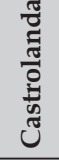 & 䒕 & 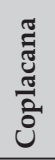 & $\begin{array}{l}\bar{F} \\
\text { J } \\
\tilde{J}\end{array}$ & 䒕 \\
\hline Supermercado & $X$ & & $X$ & & & $X$ & $X$ & & & & $x$ & $X$ \\
\hline Assistência técnica automotiva & & & & & & & & & & $X$ & & \\
\hline Farmácia & & & & & & & & & & & & $X$ \\
\hline Loja de departamento & & & & & & & & & & & & $\mathrm{X}$ \\
\hline Venda de combustível & $X$ & & $\mathrm{X}$ & $X$ & & & $X$ & & $\mathrm{X}$ & & & $X$ \\
\hline Centro atacadista & & & & & & $\mathrm{X}$ & & & & & & \\
\hline Corretora de seguros & & $X$ & & & & & & & & & & \\
\hline Comercialização de materiais de construção & & & & & & & $\mathrm{X}$ & & & & & \\
\hline Cogeração de energia elétrica & & & & $\mathrm{X}$ & $\mathrm{X}$ & & & & & & & \\
\hline Cooperativa de crédito & & $\mathrm{X}$ & & & $\mathrm{X}$ & & & & $\mathrm{X}$ & & & \\
\hline Exportadora (Off Shore) & & $x$ & & & & & & & & & & \\
\hline Cogeração de gás por meio de biodigestores & & & & & & & & $X$ & & & & \\
\hline
\end{tabular}

Fonte: Dados da pesquisa.

Especificamente em relação aos supermercados, Martins e Souza (2014) acreditam que isso se deve ao fato de ser um segmento altamente rentável. Além disso, as redes de comércio varejista são também utilizadas como elos finais da cadeia de valor do portfólio de negócios da organização cooperativa, o que pode ser compreendido como parte do processo de verticalização do empreendimento. Somente como exemplo, o faturamento com os postos de combustíveis e a rede de super- mercados foi responsável, em uma das cooperativas analisadas, por cerca de $5,9 \%$ do faturamento anual de 2013.

Além da diversificação concêntrica e conglomerada da cadeia de valor das cooperativas agropecuárias analisadas, conforme se observa (Quadro 3), com algumas poucas exceções, grande parte das cooperativas analisadas apresenta números elevados em seus respectivos quadros sociais.

Quadro 3. Número de associados e área de atuação das cooperativas pesquisadas em 2013

\begin{tabular}{|l|c|c|}
\hline \multicolumn{1}{|c|}{ Cooperativa } & No Associados & Área atuação direta \\
\hline Lar & 9.199 & SC; PR; MS \\
\hline Integrada & 7.429 & PR \\
\hline Frimesa & Cinco cooperativas* & SC; MS; PR \\
\hline Coamo & 26.276 & PR; SC; MT; MS; Paraguai \\
\hline CVale & 14.614 & PR \\
\hline Cocamar & $11.800^{* *}$ & GO \\
\hline Comigo & 6.620 & PR; DF; SP \\
\hline Copacol & 5.015 & SC; PR \\
\hline Coperalfa & 16.368 & SP; PR \\
\hline Castrolanda & 782 & SP; PR \\
\hline Capal & 1.566 & SP; MG; MS; GO \\
\hline Coplacana & 10.220 & PR; SC \\
\hline Coasul & 6.177 & SP; MT; MS; PR; GO \\
\hline Camda & 14.411 & RS \\
\hline Cotripal & 3.468 & \\
\hline
\end{tabular}

* Cooperativa Central; ** Dados referentes a 2012.

Fonte: Dados da pesquisa. 


\subsection{O perfil financeiro-contábil das maiores cooperativas agropecuárias brasileiras}

No que diz respeito ao perfil financeiro-contábil das cooperativas pesquisadas, é possível notar, pela Tabela 1, algumas peculiaridades. Destaca-se o fato de que a cooperativa central foi a que apresentou menor percentual de Custo de Produtos Vendidos/Serviços Prestados (74,48\%) em relação ao total de Receitas Líquidas. Por consequência, foi a cooperativa que apresentou valor percentual superior na Taxa de Lucro Bruto $(25,52 \%)$.

Tais informações corroboram os apontamentos feitos por Galerani (2003), Ling (2011) e Bialoskorski Neto (2012) de que uma das principais possibilidades para melhor competitividade no negócio cooperativo é o crescimento baseado na verticalização e na integralização de cooperativas singulares em empreendimentos centrais. Nesse mesmo contexto, Torgerson (2001) é enfático ao externar que cooperativas centrais seriam uma das formas principais de incremento de vantagens competitivas.

Todavia, é preciso ressaltar que a cooperativa central foi aquela que apresentou o segundo maior percentual de Despesas e Dispêndios de todas as cooperativas analisadas $(22,14 \%)$. Tal fato sinaliza que, possivelmente, isso se deve ao fato de sua complexidade superior de gestão, inclusive em relação aos custos de gestão e operação. Desse montante de Despesas e Dispêndios $(22,14 \%)$ da cooperativa central, $99,8 \%$ estavam concentrados no aspecto operacional e, desses, 57,8\% relacionavam-se a dispêndios com ingresso de vendas. Tal cenário pode estar relacionado ao fato de a cooperativa central despender maior volume de recursos no fortalecimento da marca (publicidade), maior portfólio de produtos relacionados às suas atividades principais (linhas diferentes de produtos), ou mesmo na logística de operação, haja vista ser proprietária de segmento de transporte.

Em relação às transações com não cooperados, denominada no contexto contábil de Atos Não Cooperativos, percebeu-se, no cômputo total das cooperativas pesquisadas, que tais operações não são expressivamente significativas. Isso pode ser corroborado pelo fato de que o valor máximo de ganhos com transações realizadas com não cooperados representou 1,3\% do total de Receitas Líquidas dentre os casos analisados.

A baixa representatividade de operações realizadas com não associados demonstra que as atividades econômicas das cooperativas, principais e secundárias (diversificação conglomerada) podem estar mais voltadas à prestação de serviços

Tabela 1. Resultado da Análise Vertical da D.R.E. das cooperativas pesquisadas

\begin{tabular}{lcccc}
\hline & Média (\%) & Desvio padrão (\%) & Mínimo (\%) & Máximo (\%) \\
\hline Receita Operacional Líquida & 100,0000 & 0,00000 & 100,00 & 100,00 \\
Custo dos produtos vendidos & 83,9867 & 4,61874 & $74,48^{*}$ & 91,77 \\
Sobra/ Lucro bruto & 16,0133 & 4,61874 & 8,23 & $25,52^{*}$ \\
Outros ingressos (inclusive financeiros) & 1,3947 & 1,87191 & 0,06 & 7,03 \\
Despesas e Dispêndios (inclusive financeiros) & 14,6980 & 7,27084 & 4,59 & 22,7 \\
Sobra/ Lucro antes dos impostos & 3,9200 & 1,47787 & 2,28 & 7,29 \\
Impostos & 0,2580 & 0,22571 & 0,02 & 0,68 \\
Sobra/ Lucro líquido & 3,6607 & 1,30958 & 2,19 & 6,68 \\
Ajustes & 0,2107 & 0,26007 & 0,00 & 0,71 \\
Sobra/Lucro depois dos ajustes & 3,7800 & 1,33649 & 2,07 & 6,68 \\
Destinações legais e estatutárias & 2,5733 & 1,59061 & 0,49 & 6,68 \\
Operações com terceiros** & - & - & 0,00 & 1,26 \\
Sobras a disposição da AGO*** & - & - & 0,00 & 3,84 \\
\hline
\end{tabular}

* Percentual relativo à DRE da cooperativa central; ** Algumas demonstrações analisadas não discriminavam de forma separada tal informação; *** Algumas cooperativas alocavam todas as sobras em destinações legais e estatutárias, não ressaltando, a priori, quais foram para decisões na A.G.O.

Fonte: Dados da pesquisa. 
aos associados do que a ganhos econômicos destinados à geração de lucro ${ }^{12}$, contrariando a perspectiva externada por Martins e Souza (2014).

\subsection{Análise comparativa de cooperativas e empresas não cooperativas}

Quanto à comparação dos valores médios percentuais de cada um dos itens (rubricas) analisados nas DRE's de cooperativas e empresas não cooperativas, o teste de Mann-Whitney aponta para algumas diferenças estatisticamente relevantes (Tabela 2). Ressalta-se que a hipótese nula seria a não presença de diferenças amostrais entre as diversas rubricas da DRE de empreendimentos cooperativos e não cooperativos.

A primeira constatação, visualizada na Tabela 2, é que o Custo de Produtos Vendidos das cooperativas agropecuárias analisadas é estatisticamente superior àquele de empresas não cooperativas. Tal cenário evidencia que as cooperativas despendem um volume maior de suas receitas na produção dos bens e serviços oferecidos. Sabe-se que a rubrica de custos de produtos vendidos é composta pela soma dos valores gastos com matéria-prima, mão de obra e custos indiretos de produção. Nesse sentido, qualquer um desses itens (ou todos eles) poderia elevar essa rubrica no segmento cooperativista.

Decorre que diversos estudos apontam que em cooperativas com diversificação concêntrica, dada a economia de escopo e escala alcançada, há uma diminuição dos custos indiretos de produção, conforme ressaltam Barni e Brandt (1992), Souza e Braga (2007), Britto (2013) e Martins e Souza (2014). Tal contextualização, a priori, evidencia que os custos indiretos não são os principais responsáveis pela representatividade elevada da rubrica dos custos de produtos vendidos.

12. Tudo o que é comercializado com não associados, no âmbito da contabilidade de organizações cooperativas, deve ser contabilizado à parte, uma vez que desse montante haverá a incidência de tributação sobre lucros. Logo, não se fala em lucratividade nos atos cooperativos, somente naqueles oriundos de transações com não associados.
Em relaçãoà mão de obra, alguns pesquisadores e relatórios técnicos externam que as cooperativas oferecem melhor estruturação de planos de cargos e salários (maior remuneração ao corpo de colaboradores) do que empresas não cooperativas. Tais fatos foram percebidos empiricamente nos levantamentos realizados por Drews (2000), Ronkoski (2003), Balleiro et al. (2004) e, principalmente, por levantamentos realizados pela Organização das Cooperativas Brasileiras (OCB, 2009).

Outra característica que pode ser a responsável, talvez a principal delas, para a existência de custos superiores de produção é a existência de dispêndios superiores junto aos fornecedores de matéria-prima (produtores rurais associados). Tal fato é relevante na medida em que contesta a ideia de que organizações cooperativas competitivas tendem a assumir isomorficamente práticas de mercado, especificamente em relação à aquisição de insumos ao menor valor possível. Isso, no âmbito do empreendimento cooperativista, afetaria diretamente os proprietários, que são também os fornecedores dos insumos.

Assim, a presente constatação reafirmaria o que Amodeo (1999) e Serigati e Azevedo (2013) ressaltam, ou seja, que a competitividade das cooperativas agropecuárias pode não se dar em detrimento de um cenário prejudicial ao seu quadro de associados. Haveria, portanto, a possibilidade de empreendimentos cooperativos alcançarem volumes elevados de competitividade mercadológica concomitantemente a uma remuneração satisfatória de seus associados e colaboradores. Por remuneração, entenda-se o pagamento de valores superiores aos praticados no mercado pelas matérias-primas fornecidas e serviços prestados pelo quadro de colaboradores na comparação com os valores médios praticados no mercado não cooperativo.

Em decorrência desses custos de produção mais elevados, as cooperativas agropecuárias analisadas apresentaram uma taxa de lucro bruto estatisticamente inferior ao das não cooperativas. Todavia, quando se considera apenas o Lucro Líquido/Sobras Líquidas como um critério final de análise da competitividade, entenda-se fator 
Teste de Mann-Whitney para a comparação dos valores médios de cooperativas e empresas não cooperativas para os itens da análise vertical da D.R.E.

\begin{tabular}{|c|c|c|c|c|c|c|c|}
\hline Item & Tipo empresa & $\mathbf{N}$ & Média & Desvio padrão & Min. & Máx. & $\begin{array}{l}\text { Teste Mann- } \\
\text {-Whitney U }\end{array}$ \\
\hline \multirow{3}{*}{$\begin{array}{l}\text { Receita Operacional } \\
\text { Líquida }\end{array}$} & Cooperativa & 15 & 100,0000 & 0,00000 & 100,00 & 100,00 & \multirow{3}{*}{1} \\
\hline & Empresa & 14 & 100,0000 & 0,00000 & 100,00 & 100,00 & \\
\hline & Total & 29 & 100,0000 & 0,00000 & 100,00 & 100,00 & \\
\hline \multirow{3}{*}{$\begin{array}{l}\text { Custo dos Produtos } \\
\text { Vendidos }\end{array}$} & Cooperativa & 15 & 83,9867 & 4,61874 & 74,48 & 91,77 & \multirow{3}{*}{$0,0229^{*}$} \\
\hline & Empresa & 14 & 76,2586 & 9,92486 & 60,13 & 92,18 & \\
\hline & Total & 29 & 80,2559 & 8,47618 & 60,13 & 92,18 & \\
\hline \multirow{3}{*}{ Sobra/ Lucro Bruto } & Cooperativa & 15 & 16,0133 & 4,61874 & 8,23 & 25,52 & \multirow{3}{*}{$0,0229^{*}$} \\
\hline & Empresa & 14 & 23,7414 & 9,92486 & 7,82 & 39,87 & \\
\hline & Total & 29 & 19,7441 & 8,47618 & 7,82 & 39,87 & \\
\hline \multirow{3}{*}{ Outros Ingressos } & Cooperativa & 15 & 1,3947 & 1,87191 & 0,06 & 7,03 & \multirow{3}{*}{0,2703} \\
\hline & Empresa & 14 & 6,4314 & 11,44684 & 0,00 & 37,77 & \\
\hline & Total & 29 & 3,8262 & 8,31555 & 0,00 & 37,77 & \\
\hline \multirow{3}{*}{$\begin{array}{l}\text { Despesas e Dispêndios } \\
\text { Operacionais }\end{array}$} & Cooperativa & 15 & 14,6980 & 7,27084 & 4,59 & 35,20 & \multirow{3}{*}{0,3314} \\
\hline & Empresa & 14 & 19,9986 & 13,02111 & 1,54 & 46,02 & \\
\hline & Total & 29 & 17,2569 & 10,60274 & 1,54 & 46,02 & \\
\hline \multirow{3}{*}{$\begin{array}{l}\text { Sobra/Lucro Antes } \\
\text { dos Impostos }\end{array}$} & Cooperativa & 15 & 3,9200 & 1,47787 & 2,28 & 7,29 & \multirow{3}{*}{0,3766} \\
\hline & Empresa & 14 & 6,3229 & 4,43089 & 1,28 & 13,74 & \\
\hline & Total & 29 & 5,0800 & 3,42060 & 1,28 & 13,74 & \\
\hline \multirow{3}{*}{ Impostos } & Cooperativa & 15 & 0,2580 & 0,22571 & 0,02 & 0,68 & \multirow{3}{*}{$6,82 \mathrm{E}-5^{*}$} \\
\hline & Empresa & 14 & 1,9493 & 1,51378 & 0,00 & 4,69 & \\
\hline & Total & 29 & 1,0745 & 1,35247 & 0,00 & 4,69 & \\
\hline \multirow{3}{*}{ Sobra/ Lucro Líquido } & Cooperativa & 15 & 3,6607 & 1,30958 & 2,19 & 6,68 & \multirow{3}{*}{0,8467} \\
\hline & Empresa & 14 & 4,5193 & 3,36290 & 1,03 & 10,10 & \\
\hline & Total & 29 & 4,0752 & 2,50975 & 1,03 & 10,10 & \\
\hline
\end{tabular}

* Reter a hipótese nula ao nível de significância de 0,05.

Fonte: Dados da pesquisa.

responsável pela perenidade do negócio cooperativo no contexto do setor de produção agropecuária, não há diferenças estatisticamente válidas em relação às empresas de capital (não cooperativas) e as cooperativas.

A desvantagem evidenciada na taxa de Lucro Bruto das cooperativas em comparação ao segmento de empresas de capital é revertida, notavelmente, pela rubrica relacionada aos tributos, que também apresenta diferenciação estatisticamente válida. Conforme já evidenciado anteriormente, há uma preponderância quase absoluta nas operações realizadas por meio de atos cooperativos, no âmbito das cooperativas, o que acarreta incidência tributária relacionada à renda em percentagem inferior ao de empresas não cooperativas. Esse fato, especificamente, revela a importância do tratamento tributário diferenciado, garantido pelo Estado brasileiro, à manutenção de níveis operacionais competitivos aos empreendimentos cooperativos situados no contexto do agronegócio brasileiro.

Conforme se percebe, os dados evidenciam dois aspectos importantes, o primeiro deles é que empreendimentos cooperativos no âmbito do agronegócio não são menos competitivos que empresas de capital (não cooperativas) de porte similar e atuantes no mesmo contexto de mercado, contrariando, assim, as perspectivas de Gimenes e Gimenes (2007). Ademais, as informações analisadas não permitem dizer que essa paridade competitiva se dá, pelo enfoque aqui delineado, pelas expensas de um tratamento prejudicial ao quadro social. 


\section{Considerações finais}

A inovação teórica do presente trabalho foi apontar indícios sob dois aspectos. O primeiro é que grandes cooperativas agropecuárias não são menos competitivas que empreendimentos não cooperativos situados no mesmo setor produtivo. O segundo correlaciona-se ao fato da não confirmação de práticas isomórficas assimiladas de maneira passiva pelas organizações cooperativas em questão. Não se pode, portanto, afirmar que a tendência de estruturação do segmento cooperativista, com vistas a uma maior agregação de valor e extensão da cadeia organizacional do negócio, acarretará o enfraquecimento do empreendimento.

Os dados evidenciam que, muito embora a organização cooperativa cresça em relação à sua cadeia de valor e ao quadro social, fatores necessários ao atendimento das prescrições institucionais do campo do agronegócio, ela aparentemente não renuncia às suas preocupações relacionadas ao seu quadro social.

Assim, a competitividade das grandes cooperativas, analisadas no presente trabalho, parece ser decorrente de uma busca de equilíbrio entre o custo de produção, cuja inferência advoga por uma preocupação social e política, mas também por apresentar uma cadeia de valor extensa e diversificada, com potencial poder de barganha no mercado frente aos demais agentes econômicos.

Evidenciou-se, também, a incipiência percentual de ganhos oriundos de transações com não associados. Tais fatos podem indicar que a vantagem competitiva das maiores cooperativas brasileiras do segmento de produção agropecuária, que iguala estatisticamente a "lucratividade" desse setor a empresas não cooperativas está relacionada com as transações do empreendimento com seu quadro de associados. Não se pode, a priori, considerando-se os dados alcançados nesta pesquisa, advogar pela existência de baixa participação econômica dos associados nos negócios das cooperativas analisadas, refutando os argumentos de que a ampliação do empreendimento criaria um contexto favorável ao abandono do negócio por parte do associado, sob o ponto de vista comercial. Tais fatos corroboram com os apontamentos também obtidos por Souza e Braga (2007) e Chaddad (2007) de que não necessariamente o crescimento da organização cooperativa enfraquece o negócio. Isso se denota pelo fato de que a pressão do ambiente de negócios, por ganhos de escala e escopo, possivelmente seja superior ao incremento nos custos de transação.

Há de se ressaltar, em relação à eficiência operacional, o desempenho da cooperativa central analisada, que apresentou-se com menor custo de produção, confirmando as premissas de que a fusão de empreendimentos cooperativos, a criação de empreendimentos de segundo grau e a ampliação da cadeia de valor sejam uma alternativa viável para a perenidade do segmento cooperativista agropecuário.

Confirma-se, portanto, os apontamentos de Moreira et al. (2012), de que o desempenho econômico, mensurado pela competitividade do negócio cooperativo frente às demais organizações não cooperativas pode ser uma condição para o desenvolvimento dos atores envolvidos. Tal desempenho resulta em possível melhor remuneração da produção dos associados e do corpo de colaboradores dessas organizações.

Apesar dos relevantes apontamentos alçados no presente trabalho, uma de suas limitações foi a não comprovação qualitativa das inferências externadas mediante a análise documental e financeiro-contábil. Destacadamente no sentido de se buscar um melhor entendimento dos níveis de satisfação dos associados, do quadro de colaboradores dessas organizações e da eficácia percebida no funcionamento de cooperativas centrais. Além disso, não foram confirmados, por meio de dados primários, os apontamentos teóricos e técnicos relacionados ao fato de haver maior remuneração ao quadro de colaboradores e associados no contexto das cooperativas agropecuárias brasileiras frente a empresas não cooperativas. 
O ponto frágil da pesquisa é justamente a ausência de entendimento das relações formais e informais passíveis de explicarem, de maneira mais conclusiva, o custo de produção mais elevado apresentado pelas cooperativas pesquisadas e também a eficácia relacional (aspecto social) da criação de cooperativas de segundo grau (cooperativas centrais).

Outro fator limitante é que a análise foi realizada em seção cruzada, não permitindo inferências em outros espaços temporais senão aquele em questão. Ressalta-se, todavia, que mesmo a despeito da limitação desse tipo de análise, tal prática é recorrente em trabalhos acadêmicos, conforme se percebe em Bogoni et al. (2011), Teixeira e Kassouf (2011) e outros.

Somando-se a essa questão, é possível também afirmar que diversificadas análises financeiras e contábeis poderiam dar maior robustez às conclusões obtidas. Todavia, dada a incipiência teórica do assunto abordado, os apontamentos aqui alcançados podem servir de contextualizações para futuras incursões nesse sentido.

\section{Referências}

AMODEO, N. B. P. As cooperativas agroindustriais e os desafios da competitividade. 1999. $259 \mathrm{f}$. Tese (Doutorado em Desenvolvimento, Agricultura e Sociedade) Universidade Federal Rural do Rio de Janeiro. Rio de Janeiro: UFRRJ, 1999.

ANTUNES, M. T. P. et al. A eficiência das informações divulgadas em "Melhores \& Maiores" da Revista Exame para a previsão de desempenho das empresas. Revista Contabilidade e Finanças, v. 15, n. esp., p. 41-50, 2004.

ASHFORTH, B. E. e REINGEN, P. H. Functions of Dysfunction Managing the Dynamics of an Organizational Duality in a Natural Food Cooperative. Administrative Science Quarterly, v. 20, n. 10, p. 1-43, 2014.

ASSAF NETO, A. Estrutura e análise de balanços - um enfoque econômico-financeiro. 10. ed. São Paulo: Altas, 2012.

BALLEIRO, C. F. et al. Cooperativismo é Economia Social: fortalecendo a identidade cooperativa - o Brasil
Cooperativo Mostra o seu Valor: benefícios sócioeconômicos gerados para a sociedade. In: Seminário Tendências do Cooperativismo Contemporâneo, 3, Cuiabá/MT. Anais... Cuiabá: OCB/Sescoop, 2004.

BARNI, E. J. E. e BRANDT, S. A. Descentralização, diversificação e tamanho de cooperativas agropecuárias. Revista de Economia e Sociologia Rural, Brasília, DF, v. 30, n. 1 p. 1-10, 1992.

BEKKUMM, O. V. Cooperatives Models and Farm Policy Reform - Exploring Patterns in Structure-Strategy Matches of Dairy Cooperatives in Protected vs. Liberalized Markets. Breukelen: The Netherlands Institute for Cooperatives Entrepreneurship, 2001.

BIALOSKORSKI NETO, S. Cooperativas: um ensaio sobre eficiência econômica, contratos e fidelidade. In: BIALOSKORSKI NETO, S. Workshop Internacional de Tendências do Cooperativismo. Ribeirão Preto: FEARP/ USP, 2008, p. 85-93.

. Economia e gestão de organizações cooperativas. São Paulo: Atlas, 2012. 231 p.

BIJMAN, J., HENDRIKSE, G. e OIJEN, A. Accommodating two worlds in one organization: changing board models in agricultural cooperatives. Managerial and Decision Economics, v. 34, n. 3-5, p. 204217, 2013.

BOGONI, N. M., NELSON, H. e BEUREN, I. M. Análise da relação entre crescimento econômico e gastos públicos nas maiores cidades da região Sul do Brasil. Revista de Administração Pública, v. 45, n. 1, p. 159-179, 2011.

BOLAND, M., HOGELAND, J. e MCKEE, G. Current issues in strategy for agricultural cooperatives. Choices, v. 26, n. 3, 2011. Disponível em: < http:// www.choicesmagazine.org/choices-magazine/themearticles/critical-issues-for-agricultural-cooperatives/ current-issues-in-strategy-for-agriculturalcooperatives>. Acesso em: 27 jun. 2014.

BOONE, C. e OZCAN, S. Why do Cooperatives emerge in a World Dominated by Corporations? The Diffusion of Cooperatives in the U.S. Bio-Ethanol Industry, 19782013. Academy of Management Journal, v. 57, n. 4, p. 9901012, 2014.

BRITTO, J. Diversificação, Competências e Coerência Produtiva. In: KUPLER, D. e HANSENCLEVER, L. Economia industrial. 2. ed. Rio de Janeiro: Elservier, 2013, p. 193-210.

CARDOSO, V. I. C. et al. Investimento em responsabilidade social corporativa e criação de valor nos Maiores Bancos Brasileiros. Registro Contábil, v. 4, n. 2, p. 90-104, 2013. 
082 - Competitividade e Isomorfismo: análise do perfil estrutural e financeiro-contábil de grandes cooperativas agropecuárias brasileiras

CECHIN, A. et al. Drivers of pro-active member participation in agricultural cooperatives: evidence from Brazil. Annals of Public and Cooperative Economics, v. 84, n. 4, p. 443-468, 2013a.

. et al. Decomposing the Member Relationship in Agricultural Cooperatives: Implications for Commitment. Agribusiness, v. 29, n. 1, p. 39-61, 2013 b.

CENTNER, T. J. The role of cooperatives in agriculture: Historic remnant or viable membership organization? Journal of Agricultural Cooperation, v. 3, p. 94-106, 1988.

CHADDAD, F. R. Cooperativas no Agronegócio do Leite: Mudanças Organizacionais e Estratégicas em resposta à Globalização. Organizações Rurais $e$ Agroindustriais, v. 9, p. 69-78, 2007.

.; ILIOPOULOS, C. Control Rights, Governance, and the Costs of Ownership in Agricultural Cooperatives. Agribusiness, v. 29, n. 1, p. 3-22, 2013.

CRÚZIO, H. O. Por Que as Cooperativas Agropecuárias e Agroindustriais Brasileiras estão Falindo. Revista de Administração de Empresas, v. 39, n. 2, p. 18-26, 1999.

D'ANGELO, A. C. et al. Marketing de relacionamento junto a consumidores finais: um estudo exploratório com grandes empresas brasileiras. Revista de Administração Contemporânea, v. 10, n. 1, p. 73-93, 2006.

D'AUNNO, T. A. et al. Isomorphism and external support in conflicting institutional environments: A study of drug abuse treatment units. Academy of Management Journal, v. 34, n. 3, p. 636-661, 1991.

DREWS, G. A. Gestão de Recursos Humanos orientada ao comprometimento: a prática em cooperativas do noroeste do RS. 2000, 168 f. Dissertação (Mestrado em Administração) - Universidade Federal do Rio Grande do Sul. Porto Alegre: UFRGS, 2000.

EDITORA ABRIL. Revista Exame - Melhores \& Maiores. 2013. Disponível em: <http://exame.abril.com.br/ negocios/melhores-e-maiores/ $>$. Acesso em: 10 nov. 2014.

EMELIANOFF, I. V. Economic theory of cooperation: economic structure of cooperative organizations. Edwards, 1942.

ENKE, S. Consumer cooperatives and economic efficiency. American Economic Review, v. 35, n. 1, p. 148155, 1945.

FIELD, A. Descobrindo a estatística usando o SPSS. 2. ed. Porto Alegre: Artmed, 2009.

FULTON, M. e GIANNAKAS, K. The future of agricultural cooperatives. Annual Review of Resource Economics, v. 5, p. 61-91, 2013.
GALERANI,J.Formação, estruturação eimplementação de aliança estratégica entre empresas cooperativas. RAE eletrônica, v. 2, n. 1, 2003.

GIMENES, R. M. T. e GIMENES, F. M. P. Agronegócio cooperative: a transição e os desafios da competitividade. Redes, v. 12, n. 2, p. 92-108, 2007.

HINE, S. et al. Methods of Evaluating Business Opprotunities: A Study of 70 Cooperatives in Colorado and Indiana. In: WCC-72 Annual Meeting. Las Vegas, Nevada. Proceedings... Las Vegas: WCC-72, 2001.

HOGELAND, J. A. The economic culture of US agricultural cooperatives. Culture \& Agriculture, v. 28, n. 2, p. 67-79, 2006.

JULIÁ-IGUAL, J. F. et al. Strategies developed by leading EU agrifood cooperatives in their growth models. Service Business, v. 6, n. 1, p. 27-46, 2012.

KRAATZ, M. S. e BLOCK, E. S. Organizational implications of institutional pluralism. In: GREENWOOD, R. et al. (Eds.). The Sage handbook of organizational institutionalism. London: Sage, 2008, p. $243-275$.

LEVI, Y. e DAVIS, P. Cooperatives as the "enfants terrible" of economics: Some implications for the social economy. The Journal of Socio-Economics, v. 37, p. 21782188, 2008.

LING, K. C. Cooperative theory, practice, and financing: A Dairy Cooperative case study. USDA - Research Report 221. Washington: USDA, 2011. Disponível em: $<$ http://www.rurdev.usda.gov/supportdocuments/ RR221.pdf>. Acesso em: 27 jun. 2014.

MARTINS, D. L. C. C. e SOUZA, J. P. Atributos da transação e mensuração e sua influência nas relações entre cooperados e cooperativas em sistemas agroindustriais suinícolas. Revista de Administração Mackenzie, v. 15, n. 3, 2014.

MARTINS, E., DINIZ, J. A. e MIRANDA, G. J. Análise avançada das demonstrações contábeis. São Paulo: Atlas, 2012.

MAZZAROL, T. Co-operative enterprise: A unique business model? In: Paper presented at Future of Work and Organizations. In: Annual ANZAM Conference, 25. Wellington, New Zealand. Proceedings... Wellington/ NZ:ANZAM, 2011.

MEYER, J. W. e ROWAN, B. Formal Structure as Myth and Ceremony. American Journal of Sociology, v. 83, n. 2, p. 340-363, 1977.

MICHELS, V. Uma contribuição à analise dos princípios de administração financeira aplicados a sociedades cooperativas 
de produção agrícola. 2000. 166 f. Tese (Doutorado em Contabilidade) - Faculdade de Economia, Administração e Contabilidade da Universidade de São Paulo, São Paulo, 2000.

MOREIRA, V. R. et al. O cooperativismo e a gestão dos riscos de mercado: análise da fronteira de eficiência do agronegócio paranaense. Revista de Economia e Sociologia Rural, v. 50, n. 1, p. 51-68, 2012.

NECK,H.etal.Thelandscape of socialentrepreneurship. Business Horizons, v. 52, p. 13-19, 2009.

NILSSON, J. Co-operative organizational models as reflections of the business environments. LTA, v. 4, n. 99, p. 449-470, 1999.

, SVENDSEN, G. L. H. e SVENDSEN, G. T. Are large and complex agricultural cooperatives losing their social capital? Agribusiness, v. 28, n. 2, p. 187-204, 2012.

NOVKOVIC, S. The balancing act: Reconciling the economic and social goals of co-operatives. In: Proceedings... International Summit of Cooperatives, 2012. Quebec: Quebec, 2012, p. 289-299.

OCB - Organização das Cooperativas Brasileiras. Dados consolidados de 2008. Disponível em: < http://www. ocb.org.br/gerenciador/ba/arquivos/0209_parte3_ apresentacaoocb.pdf > . Acesso em: 30 nov. 2014.

PLANAS, J. e VALLS-JUNYENT, F. ¿Por qué fracasaban las cooperativas agrícolas? Uma respuesta a partir del análisis de um núcleo de la Cataluña rabassaire. Investigaciones de Historia Económica, v. 7, p. 310-321, 2011.

PUUSA, A. et al. Mission lost? Dilemmatic dual nature of co-operatives. Journal of Co-operative Organization and Management, v. 1, p. 6-14, 2013.

REARDON, T. et al. Global change in agrifood grades and standards: agribusiness strategic responses in developing countries. The International Food and Agribusiness Management Review, v. 2, n. 3-4, p. 421-436, 1999.

RONKOSKI, J. Avaliação do processo de capacitação profissional nas cooperativas agropecuárias no Paraná. 2003, 115 f. Dissertação (Mestrado em Engenharia de
Produção) - Universidade Federal de Santa Catarina. Florianópolis: UFSC, 2003.

SANTOS, M. A. C. e LUSTOSA, P. R. B. O efeito dos componentes do lucro contábil no preço das ações. Revista UnB Contábil, v. 11, n. 1-2, p. 87-103, 2008.

SERIGATI, F. C. e AZEVEDO, P. F. Comprometimento, características da cooperativa e desempenho financeiro: uma análise em painel com as cooperativas agrícolas paulistas. Revista de Administração, v. 48, n. 2, p. 222-238, 2013.

SOUZA, U. R. e BRAGA, M. J. Diversificação concêntrica na cooperativa agropecuária: um estudo de caso da COMIGO. Gestão da Produção, v. 14, n. 1, p. 169-179, 2007

TAKAMATSU, R. T. et al. Impactos da divulgação de prejuízos nos retornos de ações de companhias participantes do IBOVESPA. Revisto Universo Contábil, v. 4, n. 1, p. 46-63, 2008.

TEIXEIRA, E. C. e KASSOUF, L. A. A Relação entre Violência nas Escolas e Desempenho Escolar no Estado de São Paulo em 2007: uma Análise Multinível. Rede de Economia Aplicada, 2011. [Working Paper, n. 9].

TORGERSON, R. E. A Critical Look at New-Generation Cooperative. Rural Cooperatives, v. 68, n. 1, p. 15-19, 2001.

TRECHTER, D. D. et al. Using communications to influence member commitment in cooperatives. Journal of Cooperatives, v. 17, p. 14-32, 2002.

VALENTINOV, V. Why are cooperatives important in agriculture? An organizational economics perspective. Journal of Institutional Economics, v. 3, n. 1, p. 55-69, 2007.

WANG, H. H. et al. Contracting, negotiation, and the policy change: the conflict between Korean farmers and their agricultural cooperatives. Agricultural Economics, v.57, n.10, p. 467-473, 2011.

WANG, X. et al. The Empirical Study on Operating Efficiency of Agricultural Cooperatives in Langao. International Journal of Business and Management, v. 7, n. 17, p. 60-69, 2012.

ZYLBERSZTAJN, D. Quatro estratégias fundamentais para cooperativas agrícolas. In: BRAGA, M. J. e REIS, B. S. (Orgs.). Agronegócio cooperativo-reestruturação e estratégias. Viçosa: Suprema, 2002, p. 55-75. 
